\title{
A RESISTÊNCIA NA LITERATURA APOCALÍPTICA DE DANIEL DO II SÉCULO a. E.C. E NO MESSIANISMO DOS TEXTOS DE MATEUS DO I SÉCULO E.C.
}

\author{
Diego Lino Silva ${ }^{1}$; Ágabo Borges de Sousa ${ }^{2}$; Gabriel Santana Silva ${ }^{3}$ e Andrey Sá Barreto \\ Souza $^{4}$ \\ 1. Bolsista PIBIC/FAPESB, Graduando em Licenciatura em História, Universidade Estadual de Feira de Santana, e-mail: \\ historia.lino@gmail.com \\ 2. Orientador, Departamento de Ciências Humanas e Filosofia, Universidade Estadual de Feira de Santana, e-mail: \\ dr_agabo@hotmail.com \\ 3. Participante do projeto As Escolas Filosóficas do II sec. a. Cr. e o Movimento Apocalíptico de Daniel, Departamento de \\ Ciências Humanas e Filosofia, Universidade Estadual de Feira de Santana, e-mail: \\ mssgabrielsantana@gmail.com \\ 4. Participante do projeto As Escolas Filosóficas do II sec. a. Cr. e o Movimento Apocalíptico de Daniel, Departamento de \\ Ciências Humanas e Filosofia, Universidade Estadual de Feira de Santana, e-mail: \\ andrey sa@hotmail.com
}

\section{INTRODUÇÃO}

PALAVRAS-CHAVE: Apocalíptica; Resistência; Messianismo.

O II século a. E.C., no Médio Crescente se caracteriza por interações culturais entre a comunidade judaica e helenística. Para alguns pesquisadores, essa experiência fala sobre manifestações de resistência identitária cultural, especialmente religiosa, dos grupos judaicos. Tais resistências se aplicam também às conflituosas interações culturais entre romanos e as comunidades cristãs primitivas no I século E.C. Foram redigidos alguns escritos como resultado desse conflituoso processo de interação. Esses escritos, consolidados em tradições canônicas véterotestamentária e neotestamentária, são analisados no presente trabalho enquanto representações de um imaginário religioso coletivo sobre a realidade histórico-social do processo de helenização e romanização. A proposta do trabalho é, sob a perspectiva da história comparada, pensar os discursos escatológicos e as representações do imaginário sobre o contexto social, na tradição antiga, através das comunidades de Daniel e Mateus.

\section{MATERIAL E MÉTODOS}

Trata-se, essencialmente, de uma pesquisa documental e bibliográfica, sob a perspectiva da história cultural, trabalhando principalmente com o conceito de representação em Roger Chartier ${ }^{1}$. Portanto, a partir da análise dos textos, identificar percepções que permitam ler o contexto cultural, político e, especialmente, religioso do período helenístico no Médio Crescente pelas formas como as tradições literárias permitem a leituras dessas culturas.

Sob a abordagem da história comparada, na perspectiva de Marcel Detienne ${ }^{2}$, no qual as comparáveis são elaboradas de acordo com a experimentação do objeto de reflexão. Amoedando, isto é, circulando entre essas culturas "[...] com duas ou três questões no bolso, como se quisesse assim estender mais largamente possível o campo de uma investigação $[\ldots]^{\prime 3}$.

E em diálogo com o método histórico-social de Rainer Kessler ${ }^{4}$, que ressalta a dinamicidade dos movimentos sociais e interage com outras ciências sociais como a antropologia, filosofia, arqueologia e entre outras. Utilizando como fonte documental,

\footnotetext{
${ }^{1}$ CHARTIER, Roger. A historia cultural: entre praticas e representacoes. Rio de Janeiro: Bertrand Brasil, Lisboa, Portugal: Difel, 1990. 239p

${ }^{2}$ DETIENNE, Marcel. Comparar o incomparável / Marcel Detienne; [tradutor Ivo Storniolo]. - Aparecida, SP: Idéias e Letras, 2004.

${ }^{3}$ Ibidem, p. 52.

${ }^{4}$ KESSLER, Rainer. História Social do Antigo Israel. Paulinas, São Paulo, 2009.
} 
principalmente, o livro canônico veterotestamentário Daniel, assim como o livro neotestamentário Mateus.

\section{ANÁLISE E DISCUSSÃO DOS RESULTADOS}

As análises dos textos em seus aspectos escatológicos foram efetuadas, seguindo à proposta do plano de trabalho. Percebeu-se ao longo da pesquisa que as interpretações sóciopolíticas dos escritos indiciam o aspecto de resistência dos mesmos, como também denunciam um ethos, uma identidade. Desde então, o debate sobre identidade cultural torna-se central no desenvolvimento da pesquisa. Identificado mais facilmente no discurso de resistência do movimento apocalíptico daniélico. Entretanto, no livro de Mateus, diante o caráter diversificado do cristianismo primitivo em sua gênese, é mais difícil delimitar características identitárias dessa comunidade.

As possibilidades sobre o discurso religioso fantástico ser, no texto daniélico, para além do resultado de uma cultura indissociável do divino, mas também estratégia de ratificar essa cultura e, por conseguinte, essa identidade, provém especialmente de duas premissas. A primeira está nas reflexões de Tomaz Tadeu da Silva ${ }^{5}$ sobre identidade, onde este afirma a vinculação da identidade às relações de poder, isto é, a identidade está envolvida em uma competição pelos recursos simbólicos e materiais da sociedade, utilizando de classificações dicotômicas que determinam limites entre "nós" e "eles". "Essa demarcação de fronteiras, essa separação e distinção, supõem e, ao mesmo tempo, afirmam e reafirmam relações de poder" ${ }^{6}$. Essa classificação compartilha da fluidez da identidade cultural que Stuart Hall ${ }^{7}$ apresenta, na qual os sujeitos que postulam uma identidade partilham de experiências históricas e códigos culturais. Estes, diante a dinamicidade da história, através da identificação, posicionam-se e reconstroem discursos sobre as identidades históricas herdadas de um passado comum conforme seus interesses: "As identidades culturais são pontos de identificação, os pontos instáveis de identificação ou sutura, feitos no interior dos discursos da cultura e da história. Não uma essência, mas um posicionamento." 8.

Uma segunda premissa se refere à perspectiva teórica que norteia a análise dos textos véterotestamentários enquanto fontes históricas. Entendendo os discursos presentes na literatura apocalíptica daniélica como representações do mundo social, forjadas de acordo com interesses dos grupos apocalípticos, especialmente o movimento de Daniel. O que destaca a perspectiva cultural de análise, que "tem por principal objeto identificar o modo como em diferentes lugares e momentos uma determinada realidade social é construída, pensada, dada a ler." 9 .

Contudo, no que se refere ao cristianismo primitivo, existe uma dificuldade de identificar determinantes identitárias em geral, tendo em vista as seguintes questões: Ao falar de cristianismo primitivo, não nos referimos a uma "nação", isto é, um grupo étnico como os judeus, mas se apresentam traçados religiosos. Portanto, é possível identificar discursos, comportamentos e representações identitárias transpassadas pelo sagrado. Para além disso, as interações culturais decorrentes de contatos ou dominações político-sociais atuam de forma diferente sobre à religiosidade cristã, sem interferir no que já está delimitado, contudo, participando da sua elaboração desde a gênese.

\footnotetext{
${ }^{5}$ SILVA, Tomaz Tadeu da (org.) Identidade e diferença: na perspectiva dos estudos culturais. Petrópolis RJ. Vozes, 2000.

${ }^{6}$ Ibidem, p. 82.

${ }^{7}$ HALL, Stuart. Identidade cultural e diáspora. Revista do Patrimônio Histórico e Artístico Nacional. № 24, p. $68-75,1996$, p. 70.

8 Ibidem, p. 70.

${ }^{9}$ CHARTIER, Roger. A história cultural entre praticas e representações. p. 16.
} 
O cristianismo, procedendo do judaísmo, implantou-se e desenvolveu-se em ambientes greco-romanos, assimilando, integrando, interagindo e reinterpretando muitos elementos socioculturais e categorias de pensamentos neles encontrados, especificamente de cunho religioso, culto de mistérios, hermetismos e gnoses pagãs. ${ }^{10}$

As conclusões de Warren Carter $^{11}$ trazem importantes considerações sobre a comunidade mateana, assim como considerações sobre as intenções que incidem sobre os escritos. Ele atribui à redação do Evangelho de Mateus a uma comunidade com características particulares, inserida em um espaço de intensa e conflituosa interação cultural, que por consequência, coloca esse grupo em situação de marginalidade e de ameaça às suas percepções culturais, mais especificamente, religiosas.

Diante disso, o livro de Mateus, segundo Carter, fala sobre uma comunidade das minorias, dos ocupantes das margens que, diante o percurso de deslocamento da estrutura romana, identificam-se na trajetória de um homem marginalizado e condenado por trair o desrespeitar a ordem civil e política de Roma. Nesse sentido, os escritos em Mateus são uma contra narrativa para além do aspecto de messiânico de defesa e esperança. A comunidade mateana também utiliza a literatura como resistência.

Os elementos mitológicos das narrativas, isto é, a figura do Cristo, por exemplo, possui intenções que dialogam e transpassam a realidade sóciopolítica. O contínuo conflito em que Jesus aparece contra a estrutura social romana, serve como reflexo de uma luta cósmica entre Deus e Satanás. Associar Jesus à condição de divindade implica em compreender o mundo atual como de pecados que se opõem aos desígnios de Deus em seus agentes humanos e estruturas políticas opressoras. Tal concepção denota um objetivo sobre o Cristo: De um libertador da realidade de oposição. Essas intensões messiânicas do livro de Mateus, condensada entre os pesquisadores do mesmo, justificam a intensão de compará-lo ao discurso apocalíptico daniélico.

\section{CONCLUSÃO}

Considerando o movimento de conflituosa interação cultural do II século a. E.C., junto às imposições de Antíoco IV Epífanes e a condição de ameaça a sua identidade que foi submetido o povo judeu. A emergência de quaisquer elementos que insinuassem a possibilidade de transgressão daquela realidade e que, por conseguinte, traga conforto e esperança, como um novo reino ou uma figura messiânica, por exemplo, pode ser parte dos interesses dos judeus no período. Daniel aparece então enquanto arquétipo de enfrentamento ideológico às determinações do soberano selêucida e da cultura helenística.

$\mathrm{Na}$ literatura apocalíptica daniélica existe a intenção de ratificar a intervenção do divino na realidade histórica através das visões apocalípticas e do discurso fantástico que estas carregam. Esse discurso serve como difusor de esperança e conforto para os sujeitos à perseguição e opressão helenística. Para os portadores do movimento apocalíptico, a condição de opressão é temporária uma vez que o futuro estaria reveladamente apresentado àqueles que permaneceram fiéis, tal como Daniel, à identidade teológica/cultural judaica, estarão com os Santos do Altíssimo no reino estabelecido pelo Messias, seguros do julgo de reis estrangeiros.

Existem significações do mundo simbólico, por meio de representações visionárias, de forma que projeções em figuras do imaginário religioso forneçam respostas à realidade de opressão helenística, reafirmando a consciência teológica da identidade cultural judaica enquanto sabedoria circunstanciada pela experiência sócio histórica.

\footnotetext{
${ }^{10}$ IZIDORO, Interações conflitos e desafios na identidade do cristianismo primitivo, p. 70.

${ }^{11}$ CARTER, Warren. O Evangalho de São Mateus: comentário sociopolítico e religioso a partir das margens / Warren Carter; tradução Walter Lisboa. - São Paulo: Paulus, 2002.
} 
A mentalidade escatológica mateana é semelhante à do livro de Daniel. Existe um reino por vir que é dado conforme a vontade de Deus (Mt 21, 43). Além de associações, que indiciam as influências, diálogos da apocalíptica de Daniel com os escritos de Mateus.

Contudo, o caráter histórico do discurso parece mais claro. Isto é, o texto se remete ao futuro, existem intensões, esperanças e representações sobre um por vir. Porém, as figuras que compõem o imaginário religioso aparecem de forma mais discreta, o presente de dor e tribulação aparece muito mais relacionado a exortações sobre o cotidiano, em defesa das práticas que integram os sujeitos a comunidade:

É importante destacar que o discurso escatológico (Mt 24, 25) é diferente da literatura apocalítica. Esse se apresenta, em sua maioria, por intermédio de sermões e parábolas. As figuras mitológicas aparecem, mas, não necessariamente, ocupam a centralidade do texto. Entre as figuras que compõem à escatologia do livro de Mateus está o Cristo, representação normalmente associada a Jesus, protagonista das narrativas do livro. O texto mateano denuncia a condição de representação construída dessa figura imaginária do Cristo como tradição compartilhada pela comunidade, uma vez que o aparecimento deste está relacionado à condição de desolação.

É perceptível que as reflexões em torno do discurso escatológico dos escritos mateanos já acontecem em detrimento dos caminhos sugeridos pela análise da apocalíptica em Daniel. Nessa perspectiva, é importante destacar que, nesse trabalho, a análise do discurso escatológico em Mateus acaba inevitavelmente perpassada pela construção de comparáveis. Compreendidas as representações daniélicas, assim como as mateanas, procuramos reconhecer as diferenças construídas. Como disse Detienne: "[...] fazendo-as funcionar umas em relação às outras." 12 .

\section{REFERÊNCIAS}

CARTER, Warren. O Evangalho de São Mateus: comentário sociopolítico e religioso a partir das margens / Warren Carter; tradução Walter Lisboa. - São Paulo: Paulus, 2002.

CHARTIER, Roger. A historia cultural: entre praticas e representacoes. Rio de Janeiro: Bertrand Brasil, Lisboa, Portugal: Difel, 1990. 239p.

DETIENNE, Marcel. Comparar o incomparável / Marcel Detienne; [tradutor Ivo Storniolo]. - Aparecida, SP: Idéias e Letras, 2004.

HALL, Stuart. Identidade cultural e diáspora. Revista do Patrimônio Histórico e Artístico Nacional. No 24, p. $68-75,1996$, p. 70.

IZIDORO, J. L. Interações conflitos e desafios na identidade do cristianismo primitivo. São Bernardo do Campo - SP. Orácula (UMESP), 2007. Disponível em: <

http://www.dhi.uem.br/gtreligiao/pdf/07\%20Jose\%20Luiz\%20Izidoro.pdf > Acesso em: Fevereiro de 2015.

KESSLER, Rainer. História Social do Antigo Israel. Paulinas, São Paulo, 2009.

\section{SILVA, Tomaz Tadeu da (org.) Identidade e diferença: na perspectiva dos estudos} culturais. Petrópolis - RJ. Vozes, 2000.

SOUSA, Ágabo Borges de. Daniel: Um Apocalipse Anticuo-Testamentário. Grupo de Pesquisa As Escolas Filosóficas do II sec. a. Cr. e o Movimento Apocalíptico de Daniel (artigo). CNPq. UEFS, DCHF, NEF. 2012.

\footnotetext{
${ }^{12}$ DETIENNE, Marcel. Comparar o incomparável, p. 67.
} 